\title{
Pulmonary Rehabilitation Improves Exercise Capacity in Subjects with Kyphoscoliosis and Severe Respiratory Impairment
}

\author{
Salvatore Fuschillo MD, Alberto De Felice MD, Michele Martucci MD, Carlo Gaudiosi MD, \\ Viviana Pisano MD, Dino Vitale MD, and Giovanni Balzano MD
}

\begin{abstract}
BACKGROUND: Patients with kyphoscoliosis and severe respiratory impairment frequently experience reduction in exercise tolerance, limitation in daily life activities, and deterioration in health-related quality of life (HRQOL). Noninvasive ventilation (NIV) as an add-on treatment to long-term oxygen therapy (LTOT) was shown to improve symptoms and HRQOL in these patients. Pulmonary rehabilitation can increase exercise capacity and HRQOL in patients with COPD, but its role in patients with restrictive thoracic disease, such as kyphoscoliosis, is uncertain. The aim of this study was to analyze the effects of combining pulmonary rehabilitation with LTOT and NIV treatments on arterial blood gases and the 6-min walk test (6MWT) in a homogeneous group of subjects with kyphoscoliosis. METHODS: Twenty-three subjects with kyphoscoliosis and respiratory failure who were being treated with both LTOT and NIV and who had been referred to a pulmonary rehabilitation program were retrospectively analyzed. Eighteen subjects were included, and there was no control group. Pulmonary rehabilitation involved educational and physical training sessions and was carried out daily for 4-6 weeks. Exercise intensity was personalized based on individual tolerance, physiologic parameters, or physiotherapist judgment. RESULTS: Upon completion of pulmonary rehabilitation, a significant improvement in 6-min walk distance was observed $(P=.04)$. The dyspnea score at the end of the 6MWT improved as well, although the improvement did not reach statistical significance $(P=.06)$. These changes were not confirmed at a 12-month follow-up visit. No significant effects of pulmonary rehabilitation on arterial blood gases were observed. CONCLUSIONS: A combined intervention including a tailored pulmonary rehabilitation program together with LTOT and NIV seems to be of short-term benefit in subjects with kyphoscoliosis and severe respiratory impairment. Key words: kyphoscoliosis; exercise capacity; 6-min walk test; pulmonary rehabilitation. [Respir Care 2015;60(1):96-101. (C) 2015 Daedalus Enterprises]
\end{abstract}

\section{Introduction}

Patients with severe chest wall deformities, such as kyphoscoliosis, are at increased risk of developing respiratory failure. ${ }^{1,2}$ When this appears, the prognosis is poor. The most disabling symptom in these patients is exercise dyspnea, which results in reduced exercise tolerance, limitation of daily life activities, and deterioration in health-related quality of life (HRQOL) ${ }^{3,4}$ Dyspnea in patients with severe chest wall deformities generally

Drs Fuschillo, De Felice, Martucci, Gaudiosi, Pisano, and Balzano are affiliated with the Pulmonary Rehabilitation Unit, and Dr Vitale is affiliated with the Clinical Epidemiology Service, Salvatore Maugeri Foundation, Scientific Institute of Telese, Telese Terme, Benevento, Italy.

The authors have disclosed no conflicts of interest. derives from disadvantaged respiratory muscles, which present an impaired capacity to generate force, with consequent reduction in inspiratory capacity and decrease in pulmonary ventilation and arterial oxygen saturation, particularly during exercise. ${ }^{5}$ Several studies have demonstrated the efficacy of noninvasive ventilation (NIV) as an add-on treatment to long-term oxygen therapy (LTOT) in improving blood gas values, exercise capacity, HRQOL, and survival in these subjects. ${ }^{1,6-9}$

\footnotetext{
Correspondence: Salvatore Fuschillo MD, Pulmonary Rehabilitation Unit, Salvatore Maugeri Foundation, Scientific Institute of Telese, Bagni Vecchi 1, 82037 Telese Terme, Benevento, Italy. E-mail: salvatore.fuschillo@fsm.it.
}

DOI: $10.4187 /$ respcare.03095 
Pulmonary rehabilitation is a multidisciplinary nonpharmacologic treatment that aims to improve dyspnea, exercise tolerance, and HRQOL in patients with chronic respiratory disorders. ${ }^{10}$ However, although there are plenty of data showing significant and clinically meaningful improvements from pulmonary rehabilitation in patients with COPD, only limited information is available to date regarding the role of pulmonary rehabilitation in patients with chronic restrictive pulmonary disease ${ }^{11}$ and, in particular, in those with severe respiratory impairment due to chest wall deformities, such as kyphoscoliosis.

The main objective of this retrospective study was to examine whether the exercise capacity of patients with kyphoscoliosis and severe respiratory impairment can be improved by adding pulmonary rehabilitation to their standard home treatment, including both LTOT and NIV. The secondary aim was to evaluate the effects of pulmonary rehabilitation at a follow-up visit performed at 12 months following completion of the pulmonary rehabilitation program.

\section{Methods}

\section{Subjects and Measurements}

Records of subjects with an established diagnosis of kyphoscoliosis who had been referred to our Pulmonary Rehabilitation Unit for a pulmonary rehabilitation program were retrospectively studied. Only clinically stable subjects with kyphoscoliosis who were receiving home treatment with both LTOT and NIV were eligible for this study. Patients with a history of cardiac disorders or other comorbidities interfering with exercise were excluded.

Twenty-three subjects were selected from our database. Three subjects were excluded from the analysis for incomplete data, and two others for being wheelchair-bound. The sample size included 18 subjects with no control group. The study was approved by our institution's ethics committee.

Before starting the pulmonary rehabilitation program, spirometry, static lung volumes, arterial blood gas analysis, nocturnal monitoring of arterial oxyhemoglobin saturation $\left(\mathrm{S}_{\mathrm{aO}_{2}}\right)$, and 6-min walk test (6MWT) were assessed in all subjects. Spirometry was performed while the subject was seated according to American Thoracic Society recommendations. ${ }^{12}$ The best of three satisfactory expiratory maneuvers was used to obtain $\mathrm{FEV}_{1}$ and FVC. Static lung volumes were determined by the helium dilution method. ${ }^{13}$ Predicted values for spirometry and static lung volumes were calculated from regression equations, with span being used as an estimate of height.

After breathing room air for at least $30 \mathrm{~min}$ and while seated, subjects underwent arterial blood gas analysis with an automated analyzer. ${ }^{14}$ The $6 \mathrm{MWT}$ was performed ac-

\section{QUICK LOOK}

\section{Current knowledge}

Patients with kyphoscoliosis and severe respiratory impairment experience reductions in exercise tolerance and deterioration in health-related quality of life (HRQOL). Noninvasive ventilation (NIV) and long-term oxygen therapy (LTOT) have been shown to improve symptoms and HRQOL in these subjects.

\section{What this paper contributes to our knowledge}

A short-term pulmonary rehabilitation program in the multidisciplinary management of subjects with severe kyphoscoliosis combined with LTOT and NIV resulted in improved exercise capacity. The long-term impact of these programs are unknown.

cording to American Thoracic Society recommendations. ${ }^{15}$ The distance covered during the test was expressed in meters and as percent of predicted. ${ }^{16}$ Dyspnea and fatigue were assessed before and after the 6MWT using the modified Borg category ratio 10 scale. ${ }^{17}$ Upon completion of the pulmonary rehabilitation program and at the 12-month follow-up, arterial blood gas analysis and the 6MWT were repeated.

We also calculated the percentage of subjects who achieved changes of $>35 \mathrm{~m}$ in the six-min walk distance (6MWD). This value was considered in a previous study as the minimum clinically important difference for 6MWD in subjects with moderate-to severe COPD and is not available for patients with kyphoscoliosis. ${ }^{18}$

\section{Rehabilitation Program}

The pulmonary rehabilitation program included educational interventions and physical training. It was carried out with daily sessions (6 sessions/week) for 4-6 weeks under the supervision of an experienced pulmonary rehabilitation physiotherapist.

The group educational sessions included breathing control, airway clearance, relaxation, nutrition, medication, and oxygen use. The exercise session consisted of general exercise, including mobilization and prevention of chest rigidity using respiratory education techniques (abdominal-diaphragmatic ventilation, thoracic mobilization, decreased respiration effort, dyspnea control), and peripheral muscle training performed on a treadmill or cycle ergometer. In selected cases, a corridor walk was also considered. Exercise intensity was personalized for each subject on the basis of individual tolerance, physiologic parameters, or physiotherapist judgment. The baseline training 
intensity of the treadmill was set at $70 \%$ of the average speed of the 6MWT. Exercise intensity was subsequently enhanced by increasing duration, speed, and possibly slope. Bicycle training intensity was guided by the subject's selfassessment using the Borg scale (score of 4-6 for dyspnea and fatigue). The duration of exercise session was $30 \mathrm{~min}$, or less when the subject deemed it necessary. An oxygen supplement was used in all subjects to maintain $\mathrm{S}_{\mathrm{pO}_{2}}$ at $>90 \%$ during exercise sessions.

\section{Statistical Analysis}

Descriptive statistics are reported as mean $\pm \mathrm{SD}$. The Shapiro-Wilk test was used to test variable distribution normality. Analysis of variance for repeated measures with the Bonferroni correction for pairwise mean comparisons was used to test mean differences between the 3 temporal measurements (at baseline [T0], after rehabilitation [T1], and $1 \mathrm{y}$ later [T2]) for variables normally distributed. The nonparametric Friedman test was employed to assess differences between the 3 temporal measurements for the non-normally distributed variables. $P<.05$ was considered significant.

\section{Results}

The baseline clinical and functional characteristics of the subjects studied are shown in Table 1 . No subject had ever smoked. All subjects presented with longstanding severe impairment of respiratory function manifesting as dyspnea and severe arterial oxygen desaturation on exercise. Oxygen therapy was required for all subjects during exercise and for 4 subjects also at rest. All subjects had been on home NIV treatment for $>1 \mathrm{y}$. Five of the subjects were not taking drugs. Seven subjects used diuretics, 7 subjects used antihypertensive drugs, 6 subjects used statins, 4 subjects used digitalis, one subject used amiodarone, and one subject used metformin. Sufficient cooperation was not obtained with 2 subjects for spirometry and with 7 subjects for lung volume determination.

The assumption of distribution normality was rejected for Borg fatigue and dyspnea scores but was accepted for all other continuous variables. Blood gas analysis results at baseline, upon completion of pulmonary rehabilitation, and at the 1-y follow-up were available for 16 of the 18 subjects and did not change significantly at all time points considered (Table 2). Baseline overnight oximetry monitoring showed in all subjects but one a mild reduction of arterial oxygen saturation. In the subject presenting with nocturnal severe arterial oxygen desaturation, it was necessary to reset the ventilator. In the group as a whole, the percent of nighttime spent with $\mathrm{S}_{\mathrm{pO}_{2}}$ below $90 \%$ was $8.9 \pm 23 \%$.
Table 1. Baseline Characteristics of the Subjects Studied

\begin{tabular}{|c|c|}
\hline Characteristic & Data \\
\hline Age (mean $\pm S D), y$ & $60.5 \pm 12.6$ \\
\hline Male/female, $n$ & $6 / 12$ \\
\hline $\mathrm{FVC}($ mean $\pm \mathrm{SD}), \%$ predicted & $32.8 \pm 10.0$ \\
\hline $\mathrm{FEV}_{1}($ mean $\pm \mathrm{SD}), \%$ predicted & $30.2 \pm 8.8$ \\
\hline $\mathrm{TLC}($ mean $\pm \mathrm{SD}), \%$ predicted & $42.6 \pm 17.0$ \\
\hline $\mathrm{VC}($ mean $\pm \mathrm{SD}), \%$ predicted & $38.5 \pm 22.9$ \\
\hline $\mathrm{RV}$ (mean $\pm \mathrm{SD}), \%$ predicted & $55 \pm 19.4$ \\
\hline $\mathrm{T}<90 \%($ mean $\pm \mathrm{SD})$ & $8.9 \pm 23.0$ \\
\hline \multicolumn{2}{|l|}{ Comorbidities $(n)$} \\
\hline Hypertension & 9 \\
\hline Hypercholesterolemia & 6 \\
\hline Cerebrovascular disease & 2 \\
\hline Cor pulmonale & 2 \\
\hline Diabetes & 1 \\
\hline Arrhythmias & 1 \\
\hline $\begin{array}{l}\mathrm{TLC}=\text { total lung capacity } \\
\mathrm{VC}=\text { vital capacity } \\
\mathrm{RV}=\text { residual volume } \\
\mathrm{T}<90 \%=\text { percent of nighttime with oxygen saturation below } 90 \%\end{array}$ & \\
\hline
\end{tabular}

The baseline 6MWD was $311 \pm 65 \mathrm{~m}$ (range of 206$426 \mathrm{~m}, 58.9 \pm 7.2 \%$ of predicted) and significantly increased to $349 \pm 77 \mathrm{~m}(66.8 \pm 8 \%$ of predicted, $P=.04)$ shortly after pulmonary rehabilitation, with a difference of $38 \pm 58 \mathrm{~m}$ (Fig. 1, see Table 2). An improvement of $>35 \mathrm{~m}$ was achieved in $38.8 \%$ of subjects. Borg fatigue and dyspnea scores at the end of the 6MWT were $2.5 \pm 2.5$ and $4.2 \pm 3.2$, respectively, and both decreased shortly after pulmonary rehabilitation to $1.9 \pm 2.6(P=.55)$ and $2.5 \pm 1.7(P=.06)$, respectively (see Table 2$)$.

The 6MWD significantly declined to $286 \pm 75 \mathrm{~m}$ (55.2 $\pm 7.5 \%$ of predicted) at the 12-month follow-up visit compared with the 6MWD shortly after pulmonary rehabilitation $(P=.005)$, with a difference of $63 \pm 64 \mathrm{~m}$ (see Fig. 1). Similarly, fatigue and dyspnea scores following the 6MWT increased to $2.8 \pm 3.3(P=.55)$ and $4.2 \pm 2.7$ $(P=.06)$, respectively (see Table 2$)$.

\section{Discussion}

Patients with severe kyphoscoliosis usually experience a decrease in oxyhemoglobin saturation during sleep and/or exercise for several years before the appearance of daytime respiratory failure at rest. ${ }^{19}$ Optimal treatment includes both LTOT and NIV. In fact, it has been reported that LTOT improves exercise oxyhemoglobin desaturation and breathlessness, but not exercise capacity, ${ }^{5}$ whereas NIV is particularly effective in controlling nocturnal episodes of hypoventilation and desaturation, also improving daytime respiratory failure and exercise capacity.1,20,21,22 Although a number of studies have demonstrated that pul- 
Table 2. Results of Blood Gas Analysis, 6MWD, Fatigue, and Dyspnea Scores During the 6MWT at Baseline, at Discharge from Pulmonary Rehabilitation, and at 1-y Follow-Up

\begin{tabular}{|c|c|c|c|c|c|c|c|}
\hline & \multirow{2}{*}{ Baseline } & \multirow{2}{*}{ After Rehabilitation } & \multirow{2}{*}{ 1-y Follow-Up } & \multirow{2}{*}{ Overall $P$} & \multicolumn{3}{|c|}{ Pairwise Comparisons } \\
\hline & & & & & T0 vs T1 & T0 vs T2 & $\mathrm{T} 1 \mathrm{vs} \mathrm{T} 2$ \\
\hline $\mathrm{pH}$ & $7.41 \pm 0.03$ & $7.42 \pm 0.04$ & $7.41 \pm 0.02$ & .85 & & & \\
\hline $\mathrm{P}_{\mathrm{aCO}_{2}}, \mathrm{~mm} \mathrm{Hg}$ & $50.2 \pm 6.3$ & $48.9 \pm 5.2$ & $48.8 \pm 5.7$ & .17 & & & \\
\hline $\mathrm{P}_{\mathrm{aO}_{2}}, \mathrm{~mm} \mathrm{Hg}$ & $62.4 \pm 12.5$ & $64.3 \pm 9.0$ & $65.6 \pm 10.4$ & .07 & & & \\
\hline $6 \mathrm{MWD}, \mathrm{m}$ & $311 \pm 65$ & $349 \pm 77$ & $286 \pm 75$ & .001 & 0.04 & 0.17 & 0.005 \\
\hline $6 \mathrm{MWD}, \%$ predicted & $58.9 \pm 7.2$ & $66.8 \pm 8$ & $55.2 \pm 7.5$ & .005 & 0.05 & 0.8 & 0.02 \\
\hline \multicolumn{8}{|l|}{ Borg fatigue score } \\
\hline Baseline & $0.7 \pm 0.9$ & $0.3 \pm 0.9$ & $0.6 \pm 1.1$ & .46 & & & \\
\hline End of test & $2.5 \pm 2.5$ & $1.9 \pm 2.6$ & $2.8 \pm 3.3$ & .55 & & & \\
\hline \multicolumn{8}{|l|}{ Borg dyspnea score } \\
\hline Baseline & $0.3 \pm 0.8$ & $0.05 \pm 0.2$ & $0.3 \pm 0.5$ & .31 & & & \\
\hline End of test & $4.2 \pm 3.2$ & $2.5 \pm 1.7$ & $4.2 \pm 2.7$ & .06 & & & \\
\hline $\begin{array}{l}6 \mathrm{MWD}=6 \text {-min walk distan } \\
6 \mathrm{MWT}=6 \text {-min walk test } \\
\mathrm{T} 0=\text { at baseline } \\
\mathrm{T} 1=\text { after rehabilitation } \\
\mathrm{T} 2=1 \text { y later }\end{array}$ & & & & & & & \\
\hline
\end{tabular}

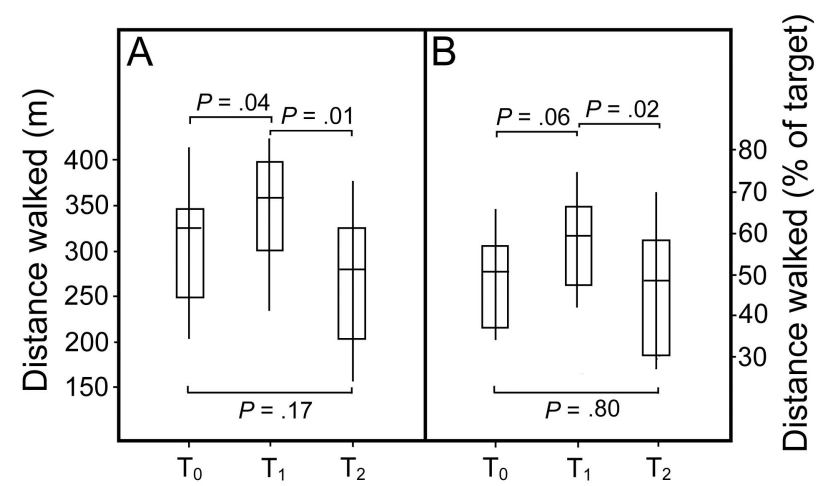

Fig. 1. A: Boxplot of walked meters. B: Walked meters as percent of target. Bonferroni corrected pairwise comparisons are reported. T0, T1, and T2 are the admission, discharge, and 1-y follow-up, respectively. Boxes include the median and are limited by the interquartile range; whiskers denote the 10th and 90th percentiles.

monary rehabilitation benefits patients with obstructive pulmonary diseases, especially COPD, ${ }^{23,24}$ its role in patients with restrictive pulmonary diseases has not been sufficiently evaluated. ${ }^{25}$ Among the few reports available, Salhi et al ${ }^{11}$ studied the effects of a 24 -week pulmonary rehabilitation program in a heterogeneous group of 31 subjects with restrictive pulmonary diseases, including 11 subjects with kyphoscoliosis, and reported significant improvements in exercise capacity, muscle force, and dyspnea.

In this study, we investigated the effect of a 4-6-week pulmonary rehabilitation program on functional exercise capacity in a highly homogeneous group of subjects with kyphoscoliosis and severe respiratory impairment who were receiving optimal home treatment with both LTOT and NIV. Our results show substantial improvements in exercise capacity upon completion of the pulmonary rehabilitation program. Dyspnea scores after the 6MWT improved as well, but the improvement was not statistically significant.

The 38-m increase in 6MWD we observed is substantially lower than the 54-m minimum clinically important difference that was reported by Redelmeier et $\mathrm{al}^{26}$ for subjects with COPD and that is widely used in clinical trials to establish a clinically relevant change in 6MWD. However, Puhan et al reported a 35-m increase in 6MWD as an important change in subjects with moderate-to-severe $\mathrm{COPD}^{18}$ and, in a subsequent study, proposed a change of $26 \pm 2 \mathrm{~m}$ to be an acceptable value for the minimum clinically important difference in subjects with severe COPD. ${ }^{27}$ In this regard, the mean $38-\mathrm{m}$ improvement observed by us is well above the proposed $26 \mathrm{~m}$ for the minimum clinically important difference and could be considered to have clinical importance in our severely compromised subjects.

An important question to address is whether the observed improvement in both 6MWD and exercise dyspnea translates into increased functional capacity during the activities of daily life and/or improved HRQOL. In a recent study of a group of subjects with chronic respiratory failure due to kyphoscoliosis, Cejudo et $\mathrm{al}^{28}$ reported that exercise training improved exercise capacity, peripheral muscle strength, and HRQOL. The mean $67.2 \mathrm{~m}$ increase in shuttle walk distance they reported was far greater than the mean $38 \mathrm{~m}$ increase reported by us, despite the similar functional characteristics presented by the two study populations and the significant relationship existing between 
the 6MWT and shuttle walk test results. ${ }^{29}$ One potential explanation for the observed difference between the two studies is the duration of the pulmonary rehabilitation program: 4-6 weeks in our study and 12 weeks in the Cejudo study. ${ }^{28}$ In fact, significantly greater improvements in exercise tolerance and dyspnea have been reported in subjects with restrictive lung diseases following a 24-week pulmonary rehabilitation program compared with a 12 week program. ${ }^{11}$

In this study, the benefit of pulmonary rehabilitation in terms of improved exercise capacity was completely lost at the 12-month follow-up visit. Our results agree with data reported by Sewell et al ${ }^{30}$ showing that important improvements in exercise tolerance in subjects with COPD were obtained after just 4 weeks of exercise but were loss 6 months later.

A significant issue of pulmonary rehabilitation is its duration, which can affect its short-term and long-term effects. Indeed, maintenance of gains in exercise tolerance at a 1-y follow-up have been reported after 20 weeks of exercise training compared with 8 weeks in subjects with COPD. ${ }^{31}$ The rapid short-term gain in exercise capacity we observed in our subjects can result from overcoming the deconditioned physical status generally presented by patients with kyphoscoliosis. Indeed, because of their deformity or instructions to avoid strenuous exertion, patients with kyphoscoliosis are generally unwilling to participate in aerobic physical activities and follow a substantially sedentary lifestyle. Loss of the gain in exercise capacity observed in our study at the 1-y follow-up could have resulted from diminished physical fitness due to a low level of daily physical activity. Unfortunately, daily physical activity was not assessed in our study. Our results are potentially relevant and suggest that structured maintenance out-patient and/or domiciliary pulmonary rehabilitation programs should be evaluated for patients with kyphoscoliosis, similar to what is recommended for patients with COPD. ${ }^{32}$

Despite reporting findings of potential clinical importance, the retrospective design and the absence of a control group limit the validity of our observed outcome. However, our study group was far more homogeneous than the subject groups included in previous trials. ${ }^{11}$ Only subjects with severe respiratory impairment due to kyphoscoliosis were enrolled in our study.

\section{Conclusions}

Our results reinforce the relevance of pulmonary rehabilitation in the multidisciplinary management of patients with severe kyphoscoliosis. A combined intervention consisting of a tailored pulmonary rehabilitation program with LTOT and NIV may contribute to a beneficial outcome in patients with kyphoscoliosis and severe respiratory im- pairment. Additional prospective controlled studies are needed to address unanswered questions, such as how to optimize training to increase benefit, how to maintain the benefit obtained and prevent its decline, and most importantly, what strategy to adopt to promote long-term adherence to exercise training.

\section{REFERENCES}

1. Fuschillo S, De Felice A, Gaudiosi C, Balzano G. Nocturnal mechanical ventilation improves exercise capacity in kyphoscoliostic patients with respiratory impairment. Monaldi Arch Chest Dis 2003; 59(4):281-286.

2. Pehrsson K, Bake B, Larsson S, Nachemson A. Lung function in adult idiopathic scoliosis: a 20 year follow up. Thorax 1991;46(7): 474-478.

3. Kesten S, Garfinkel SK, Wright T, Rebuck AS. Impaired exercise capacity in adults with moderate scoliosis. Chest 1991;99(3):663666.

4. Cejudo P, López-Márquez I, Lopez-Campos JL, Ortega F, Bernal CC, Márquez E, et al. Factors associated with quality of life in patients with chronic respiratory failure due to kyphoscoliosis. Disabil Rehabil 2009;31(11):928-934.

5. Jones DJ, Paul EA, Bell JH, Wedzicha JA. Ambulatory oxygen therapy in stable kyphoscoliosis. Eur Respir J 1995;8(5):819-823.

6. Brooks D, De Rosie J, Mousseau M, Avendaño M, Goldstein RS. Long term follow-up of ventilated patients with thoracic restrictive or neuromuscular disease. Can Respir J 2002;9(2):99-106.

7. Buyse B, Meersseman W, Demedts M. Treatment of chronic respiratory failure in kyphoscoliosis: oxygen or ventilation? Eur Respir $\mathbf{J}$ 2003;22(3):525-528.

8. Gonzalez C, Ferris G, Diaz J, Fontana I, Nuñez J, Marín J. Kyphoscoliotic ventilatory insufficiency. Effects of long-term intermittent positive-pressure ventilation. Chest 2003;124(3):857-862.

9. Gustafson T, Franklin KA, Midgren B, Pehrsson K, Ranstam J, Ström K. Survival of patients with kyphoscoliosis receiving mechanical ventilation or oxygen at home. Chest 2006;130(6):1828-1833.

10. Spruit MA, Singh SJ, Garvey C, ZuWallack R, Nici L, Rochester C, et al. An official American Thoracic Society/European Respiratory Society statement: key concepts and advances in pulmonary rehabilitation. Am J Respir Crit Care Med 2013;188(8):e13-e64.

11. Salhi B, Troosters T, Behaegel M, Joos G, Derom E. Effects of pulmonary rehabilitation in patients with restrictive lung diseases. Chest 2010;137(2):273-279.

12. Miller MR, Hankinson J, Brusasco V, Burgos F, Casaburi R, Coates A, et al. Standardisation of spirometry. Eur Respir J 2005;26(2): 319-338.

13. Wanger J, Clausen JL, Coates A, Pedersen OF, Brusasco V, Burgos F, et al. Standardisation of the measurement of lung volumes. Eur Respir J 2005;26(3):511-522.

14. American Association for Respiratory Care. AARC clinical practice guideline. Sampling for arterial blood gas analysis. Respir Care 1992; 37(8):913-917.

15. ATS Committee on Proficiency Standards for Clinical Pulmonary Function Laboratories. ATS statement: guidelines for the six-minute walk test. Am J Respir Crit Care Med 2002;166(1):111-117.

16. Enright PL, Sherrill DL. Reference equations for the six-minute walk in the healthy adults. Am J Respir Crit Care Med 1998;158(5 Pt 1): 1384-1387.

17. Mahler DA, Horowitz MB. Perception of breathlessness during exercise in patients with respiratory disease. Med Sci Sport Exerc 1994;26(9):1078-1081. 


\section{Pulmonary Rehabilitation in Kyphoscoliosis}

18. Puhan MA, Mador MJ, Held U, Goldstein R, Guyatt GH, Schünemann HJ. Interpretation of treatment changes in 6-minute walk distance in patients with COPD. Eur Respir J 2008;32(3):637643.

19. Guilleminault C, Kurland G, Winkle R, Miles LE. Severe kyphoscoliosis, breathing and sleep. Chest 1981;79(6):626-630.

20. Carroll N, Branthwaite MA. Control of nocturnal hypoventilation by nasal intermittent positive pressure ventilation. Thorax 1988;43(5): 349-353.

21. Ellis ER, Grunstein RR, Chan S, Bye PT, Sullivan CE. Noninvasive ventilatory support during sleep improves respiratory failure in kyphoscoliosis. Chest 1988;94(4):811-815.

22. Annane D, Orlikowski D, Chevret S, Chevrolet JC, Raphaël JC. Nocturnal mechanical ventilation for chronic hypoventilation in patients with neuromuscular and chest wall disorders. Cochrane Database Syst Rev 2007;17(4):CD001941.

23. Troosters T, Casaburi R, Gosselink R, Decramer M. Pulmonary rehabilitation in chronic obstructive pulmonary disease. Am J Respir Crit Care Med 2005;172(1):19-38.

24. Clini E, Ambrosino N. Rehabilitation in COPD patients: evergreen in pneumology and beyond. Eur Respir J 2011;38(3):514-515.

25. Naji NA, Connor MC, Donnelly SC, McDonnell TJ. Effectiveness of pulmonary rehabilitation in restrictive lung disease. J Cardiopulm Rehabil 2006;26(4):237-243.
26. Redelmeier DA, Bayoumi AM, Goldstein RS, Guyatt GH. Interpreting small differences in functional status: the six minute walk test in chronic lung disease patients. Am J Respir Crit Care Med 1997; 155(4):1278-1282.

27. Puhan MA, Chandra D, Mosenifar Z, Ries A, Make B, Hansel NN, et al. The minimal important differences of exercise tests in severe COPD. Eur Respir J 2011;37(4):784-790.

28. Cejudo P, López-Márquez I, López-Campos JL, Márquez E, de la Vega F, Barrot E, Ortega F. Exercise training in patients with chronic respiratory failure due to kyphoscoliosis: a randomized controlled trial. Respir Care 2014:59(3):375-382.

29. Singh SJ, Morgan MD, Scott S, Walters D, Hardman AE. Development of a shuttle walking test of disability in patients with chronic airways obstruction. Thorax 1992;47(12):1019-1024.

30. Sewell L, Singh SJ, Williams JE, Collier R, Morgan MD. How long should outpatient pulmonary rehabilitation be? A randomized controlled trial of 4 weeks versus 7 weeks. Thorax 2006;61(9):767771.

31. Swerts PM, Kretzers LM, Terpstra-Lindeman E, Verstappen FT, Wouters EF. Exercise reconditioning in the rehabilitation of patients with chronic obstructive pulmonary disease: a short- and long-term analysis. Arch Phys Med Rehabil 1990;71(8):570-573.

32. Troosters T, Casaburi R, Gosselink R, Decramer M. Pulmonary rehabilitation in chronic obstructive pulmonary disease. Am J Respir Crit Care Med 2005;172(1):19-38. 